\title{
Victoria University
}

\section{Megan Evans and Enza Gandolfo}

\section{Collaborating with the enemy}

\begin{abstract}
:
Practice-led research is by its very nature multi-disciplinary. This means that often both the student and the supervisor find themselves, from the very beginning of the project, working across a range of familiar and unfamiliar fields. The postgraduate students we have supervised in the visual arts and creative writing have engaged with ideas ranging from racism to erotica, from blindness to cannibalism; they have situated themselves in literary studies, in cultural studies, in feminist and art theory. The best of these projects produce innovative and challenging artworks/creative texts. The exegesis is often a hybrid and 'messy text' with multiple voices and perspectives.

As a writer and an artist with experience working in a range of collaborative creative arts projects, and more recently as supervisors of PhDs and MAs in visual art and creative writing, we have found that some of the elements of, and processes used in, successful collaboration also enhance supervision of practice-led postgraduate research supervision. While higher degree research belongs to, and must always be the work of, the individual student, like any good collaboration it cannot be achieved without significant and engaged dialogue, and a joint commitment by student and supervisor to the project.

In this article, we draw on our extensive experience as collaborators both in university research projects and in other contexts, on cultural-historical theories that place emphasis on the social sources of knowledge development, and on postgraduate supervision scholarship. We will distinguish the different elements of successful collaboration in a creative context and the way in which these elements can be applied to the supervision of practice-led postgraduate research projects in the visual arts and creative writing.
\end{abstract}

\section{Biographical note:}

Dr Megan Evans's PhD research was on the relationship between the virtual and the sublime. Megan has a career involving a broad spectrum of art practices from major public artworks to exhibition work. Her artwork explores landscape and colonisation in a contemporary context and investigates ideas of place. She has worked as a professional artist for over 25 years. She is currently lecturing at Victoria University in the Bachelor of Creative Art Industries. 
Dr Enza Gandolfo is a Melbourne writer. She works at Victoria University as a lecturer in creative writing and is currently supervising both MA and PhD students. Enza has a $\mathrm{PhD}$ in creative writing and her short stories, essays, autobiographical pieces, reviews and articles have been published in a range of literary journals, magazines and newspapers. Her novel, Swimming, was published by Vanark Press in August 2009.

Keywords:

collaboration - collaborative research practice 


\section{Introduction: context}

The aim of this paper is to distinguish the elements of successful collaboration in a creative arts context and to explore the ways in which these elements can be adopted and applied to postgraduate supervision. Our particular focus is on practice-led research in visual arts and creative writing for $\mathrm{MA}$ and $\mathrm{PhD}$ projects; however, we believe that taking a collaborative approach has broader applications across all spheres of creative arts research in Australia and internationally.

We are committed to the collaborative process in both our own creative practice and our academic work. For us, the benefits of working collaboratively are obvious and multiple. A number of academics in the creative arts as well as other disciplines have also advocated a collaborative approach to postgraduate supervision (Bartlett \& Mercer 2001; Nightingale 2005; Kroll \& Brien 2006; Brien 2007). In this paper, we will draw on this scholarship, on our extensive experience as collaborators and on cultural-historical theories that place emphasis on the social sources of knowledge development, to consider the application of collaborative models to creative arts supervision. We have both had significant and substantial experience supervising MA and honours students and have been supervising doctoral students for the last four years. We have brought to our supervision practice our experience as postgraduate students, teachers, practitioners, researchers and collaborators. While various approaches - mentor, teacher, guide - can be bought to supervision, we have found that collaboration is the most successful. It acknowledges that the nature of practiceled research is multi-disciplinary, and that often both the student and the supervisor find themselves, from the very beginning of the project, working across a range of familiar and unfamiliar fields.

The value of collaboration in research has been well documented:

Although in the popular imagination science remains the province of the lone genius working alone in the lab, in fact it is in, more ways than one a profoundly collective enterprise ... A classic example ... was the discovery, in 1994, of the quantum particle called the 'top quark'. When the discovery was announced, it was credited to 450 different physicists. (Surowiecki 2004: 161)

The Australian Research Council, the key statutory authority within the Australian Government's Innovation, Industry, Science and Research portfolio, with responsibility for advising the government on research matters and managing the National Competitive Grants Program, has specific programs and schemes aimed at encouraging collaboration. The Linkage International, for example, includes among its key aims to 'foster collaboration and networking between Australia-based and overseas researchers' (Australian Research Council 2009). Universities and other research institutions often acknowledge and encourage collaboration through specific policies and procedures. Victoria University, for example, has included a commitment to collaboration in its mission statement: 'We work collaboratively to develop the capabilities of individuals, enterprises and communities ... to build sustainable futures for ourselves and our stakeholders' (Victoria University 2008: 6). 
Despite this rhetoric, however, collaboration remains difficult in universities and other academic institutions because they are individualistic and hierarchical in nature. They are structured both institutionally and conceptually in ways that are not conducive to working with others, and rewards for achievement continue to be mostly individual (Brien 2007: 161). There are numerous examples in academic protocols and policies of the way in which individualism is endorsed and encouraged. One example is the varying status of first and second named authors in academic publications:

What if there is acknowledged equal authorship? We struggle with the alphabetical resolution as the same person would always be second author and institutional and political measurement often delegates the second author as having a lesser role. (Tynan $=$ Garbett 2006 sic $)$

Another example is the declaration of individual work that students are obliged to make when they submit a PhD thesis: 'Except where otherwise indicated, this thesis is my own work' (example from Victoria University). The competitive nature of academic appointment, promotion and funding schemes means that researchers often feel a need to guard their work from fellow researchers in order to maintain jobs and status and secure research funding. In addition, universities are organised by disciplines, which set up knowledge territories and boundaries that can be difficult to work across. As Foucault points out in Discipline and punish, the hierarchical institutional structures that we live with today come from a military past, designed for battle (1979). In this context, collaboration in universities is often seen as 'cooperat[ing] traitorously with the enemy' (Rawlinson 2006: 121).

The arts are no more receptive to collaboration than universities; collaborative practice is the poor cousin of the mainstream art world:

Collaborative art practices emerge and flourish under specific art-historical circumstances ... certain forms of collaboration have always characterised artistic activity, both between artists and people from other walks of life. But because the symbolic economy of recognition that characterises the art world is highly competitive, and based on the strategic exploitation of disparities in talent and social capital, permanent risk management, acceptance of and even insistence upon non-monetary remuneration and so on, sincere attempts at collaboration are easily thwarted. (Wright 2004: 534)

Even as, in these postmodernist and poststructuralist times, we recognise that no artwork or text is made/created/produced in a vacuum, it is the individual artist/writer and his/her individualism that are rewarded. Modernist principles have been theoretically challenged but have not functionally shifted. Most of us are willing to acknowledge that nothing happens in isolation and that every idea and breakthrough is building on previous ideas and breakthroughs. Despite the cliché of the artist as genius, one artist who works collaboratively says:

Artists are thieves in the attic. They far from innocently try out different, sometimes almost forgotten identities in the chaotically organized attic of history, rummaging in 
dusty, dark rooms where variations of authorial identity are stored away from view (Green 2001: ix).

The field may be aware of the prevalence of collaboration and its benefits to creative work, but continues to want to identify and reward the individual. Major arts prizes and awards are individual. Even in the most collaborative areas such as filmmaking, where teams are involved in bringing the initial vision to fruition, it is the director's name that is usually associated with a successful film.

It is with an awareness of this framing environment that we venture into this exploration of collaborative practice in postgraduate supervision. Underlying our approach to this exploration are two beliefs. First, we believe that no new work, discovery or invention is ever a result of the purely individual work of a single person. None of us do anything in complete isolation; we are all always building on the work of others. In this sense, everything is a result of some form of collaboration. While we may choose to call the role of others in the development of our work 'inspiration' or 'influence' or even 'education' rather than 'collaboration', it is important to acknowledge that 'learning and thinking [are] social processes' (JohnSteiner 2000: 3) and we are all 'thieves in the attic'. Second, we believe that working collaboratively has many rewards for the individuals who make up the collaborative teams, for the institution/s, and for the communities that will ultimately benefit from the outcomes of the works produced:

The notion of the solitary thinker still appeals to those molded by the Western belief in individualism. However, careful scrutiny of how knowledge is constructed and artistic forms are shaped reveals a different reality. Generative ideas emerge from joint thinking, from significant conversations and from sustained, shared struggles to achieve new insights by partners in thought. (John-Steiner 2000: 3)

In this context, collaboration can be seen as a postmodern practice, a setting aside of the singular view, to allow for more than one vision to coalesce into a creation of an outcome that is beyond the capabilities of the individual. It is a move away from a military mindset of battle and defence to one of conciliation and creativity. By distinguishing collaboration as a practice, and exploring the key elements that make for successful collaboration, we hope to open up the possibility of diverse collaborative practices and for collaborative work in postgraduate supervision.

\section{What is collaboration?}

Collaboration comes in many guises. Bigliazzi and Woods define collaboration as 'a hermeneutical interpretative strategy, offering a way out of oversimplified and reductive binary codifications' (2006: 1). For Bennis and Biederman, it is an opportunity to be 'liberated for a time, from the prison of the self' (cited in JohnSteiner 2000: 3). For Paul Carter, 'it is what begins to happen wherever artists talk about what they are doing, in that simple but enigmatic step, joining hand, eye and mind in a process of material thinking' (2007: xiii). These definitions of collaboration reference a freedom of sorts. In these terms, collaboration provides access to ways of 
working and thinking that cannot be achieved through individual research or practice; it allows for 'creation that transcends individual talent and skill' (Schrage 1990: 41).

So, what is this liberating practice? At a simple level, collaboration is a process that involves two or more people working together to achieve a result that is distinct from that which an individual could have produced working on her own. We agree with John-Steiner, that collaboration is also 'rooted in principles of shared responsibility ... and a commitment to a dialogic exchange' (John-Steiner 2000: 3). However, we disagree with John-Steiner's proposition that a key element of collaboration is 'negotiation'. Negotiation is often required when there is a 'battle' of ideas - akin to a 'battle over territory'. This notion is oppositional and unhelpful when the solution arrived at in collaborative work is regularly a compromise. We advocate the dialogic as a more open, less ego driven, approach in which ideas are not 'owned' and fought over but, instead, evolve. As proposed below, some models of collaboration can engender a merging of identities so that the same idea arises from two or more people. The result is not a 'compromise' position but an optimum one. It is also true, however, that collaborative practice runs along a vast spectrum. There are different models and each collaboration is unique. We will outline and explore some of these models below.

\section{Why collaborate?}

As an artist and a writer, we love to work alone, to sit at the computer and compose text or stand in front of the canvas and paint. We love the intimacy of this kind of work. We love its rhythm. Enza loves the solitary work of fiction making. Megan loves the solitary work of art making. We both acknowledge that our fiction and art are built on the work of other writers and artists, but overall the experience of this process is individualistic. However, it is important for us to combine this work in collaborative projects. Collaboration is exciting because it requires relationship and dialogue. It nourishes us creatively and contributes to our solo work. It allows for the creation of something beyond what could be imagined by us as individual artist or writer. We love the synergy of the process that produces tangents to the work previously unthought of and often surprising.

At the outset, collaboration is discomforting and challenging and yet less intimidating than working alone. The individual shares the making with someone else. He or she has to work to articulate their individual vision to another person - to share those first ideas that often seem not very good. However, there is also excitement and comfort in knowing others have a commitment to, and are, invested in the project. In collaboration, there is an opportunity to share and learn in what John-Steiner calls 'mutual appropriation' (2000: 3). In the best collaborations, the condition of joint ownership and responsibility and commitment to the other person and the project makes it easier to take risks. The inbuilt critical feedback mechanism makes it possible for individuals to say what they think, and to try new methods and techniques. Because collaborations are often interdisciplinary, they give individuals permission to move into areas they might not otherwise have ventured. In this way, 
collaboration provides an opportunity for professional development, and in our experience collaboration is usually a rich learning process.

In postgraduate research projects, as in all research aiming to develop new knowledge and make a significant original contribution, risk-taking is essential. A collaborative approach provides a safe harbour for students and supervisors to try out new ideas, methodologies and practices within this supportive framework.

\section{Models of collaboration}

There are different models of collaborative practice and each collaboration is, by its very nature, unique. In their book Single texts/plural authors (1990), Lisa Eade and Andrea Lunsford analyse conversations between collaborators to develop models of collaborative writing. They propose two models: the hierarchical model, which is highly structured and goal orientated, and in which individuals have clearly defined roles and tasks; and the dialogic model, where roles are flexible and fluid and there is more cooperation and less competition.

For the purpose of this paper, we have divided collaborative practice into four main models. As there are so many variations in the way that collaboration might be approached, we think Eade and Lunsford's two models are too restrictive. However, we acknowledge that within each of our models there are also many variations. The purpose here is not to be definitive but to provide an overview and some examples so that collaboration can be distinguished from other approaches to working and researching. We will use these models to explore the ways in which collaboration might be transferred to and/or applied in academic institutions for the supervision of students in the creative arts.

At one end of our spectrum is a practice we call 'major' collaboration. This would be closest to Eade and Lunsford's dialogic model. In this form of practice, two or more people are working together on a project or artwork, all contributing hands are joined and indistinguishable, and the individual disappears into the collective. At the other end of the spectrum is the kind of collaboration we call 'minor', where an artist or writer has a vision or idea for a project and then invites other artists or artisans to participate in the project as collaborators. The main artist may not have the skills required to realize the project and the collaboration brings others to the project to contribute their expertise and help realize the main vision. This is a more hierarchical structure because the key driver of the project is the person controlling the vision.

In both these models, there is a varying degree of commitment to relinquishing the ego and surrendering to the process so that new ideas can emerge - including ideas that do not belong to any one individual. This happens by creating opportunities for engaged and respectful dialogue. At the 'major' end of the continuum, this happens throughout the project and the 'individual' disappears. At the 'minor' end of the continuum, this may only happen within particular sections or aspects of the project. 'Major' and 'minor' are not equated with, or valued as, 'good' or 'bad' here, but with the level at which the individual disappears. 


\begin{tabular}{|l|l|}
\hline Minor collaboration & $\begin{array}{l}\text { Model 1 } \\
\text { Traditional academic model }\end{array}$ \\
\hline & $\begin{array}{l}\text { Model 2 } \\
\text { Thematically linked project }\end{array}$ \\
\hline Majer collaboration 3 \\
One product with joint vision and commitment \\
$\begin{array}{l}\text { Model } 4 \\
\text { One product and no distinction between each } \\
\text { participant }\end{array}$ \\
\hline
\end{tabular}

Table 1 Models of collaboration

Model 1 is the traditional scientific academic model, and also the film industry model. The vision for a film is usually the director's vision. The director brings together practitioners who have distinct skills. In the academic context, there is usually a key investigator who drives the project. Research assistants and postgraduate students do some of the research work and have some intellectual and creative input. In this model, the project leader - director or key investigator - takes responsibility for the project and usually gets most, if not all, the credit for success.

Model 2 is the thematically linked project. In this case, there is usually a group of individual producers (artists, writers, researchers) who are brought together by one person and under one idea or concept. The collaborative vision is at a conceptual level. Each person's work is a separate product and their contribution to the whole is distinguishable. All of the individuals share the credit. Below, Megan describes an example from 'Black on White', a collaborative project with artist Maree Clarke:

This collaboration came about as a result of an ongoing conversation between Maree and I about reconciliation. We commissioned six Indigenous artists to create work based on their representations of non-Indigenous peoples for an exhibition at the Centre for Contemporary Art in Melbourne. Each artist approached the theme in a very different way. Both Dianne Jones and Christian Thompson were amused by and somewhat critical of the distinction drawn between Indigenous and non-Indigenous. Dianne Jones made portraits of her nieces and nephews in the pose held by the Mona Lisa and set them against Leonardo's background. Other artists were more historical in their approach. The theme was what connected them. In this project, there were several collaborations: between myself and Maree as co-curators; between curators and artists; and between the works which were made individually. The theme created a dialogue between them in the gallery space. This kind of collaboration is not uncommon in the process of curating exhibitions; however, the commissioning of work based on a specific theme is not so common.

In Model 3, there is one product created. There is a joint vision and commitment, and the concept is shared but it is possible to distinguish between the contribution made by different participants at the level of technique, medium, style and/or discipline. 
One example might be a novel where each writer has written a different chapter. All of the individuals share the credit. Enza gives this example from her collaboration with visual artist Sue Dodd on the creative arts research project 'Op shopping: more than retail therapy':

From our first meeting, and a passing comment on a jacket, Sue and I began discussing opportunity or charity shops, sharing our favourite op shop stories and then finally brainstorming project ideas. We designed the project around our particular creative interests - creative writing for me, and visual and performing arts for Sue. We spent half a day a week, for about four months, together in local op shops. We interviewed volunteers and shoppers; we shopped; we took photos; Sue filmed and sketched; I took notes. The project developed as we worked together over the six months or so and in the end, we produced a book, an installation and performance. Some aspects of the project can be distinguished. I did most of the writing. Sue did all of the filming. I did more work on the book. Sue did more of the design work for the exhibition. However, neither the book nor the installation would have taken the shape they did if we had not been collaborating on the project. It was the continual discussion - of our observations, of the interviews and the stories, of the objects - that allowed the book and installation to take shape. Sue came up with the design for the installation; it was her initial idea. However, all sections have the imprint of both our hands. We worked well together, partly because we took the time to develop our relationship before the project began but also because we were in constant dialogue during the project. We were honest with each other about our concerns and anxieties, and we worked through all decisions.

In Model 4, there is one body of work produced and it is impossible to distinguish who has produced which section. An example of 'major' collaboration in the arts is the work of Charles Brown and Lyndal Green who work together on one painting. Their individual hands are invisible. They research the work together and speak of the synchronicity of independently coming up with the same idea:

We both work on each part of every painting. We work co-operatively and hate dissent ... Neither of us can ever remember who pressed the button to release the camera shutter. We can't remember who did what at all. Early on, we imagined our collaboration would produce a third hand, an imaginary artist, not him or me ... but people preferred Brown \& Green. (Brown \& Green 2008)

Megan has worked on such a 'major' collaborative project with artist Gayle Maddigan. Gayle and Megan were commissioned to make a work that would celebrate the centenary of the Eureka Stockade, to be sited at the Ballarat Botanical Gardens. In Megan's words:

Gayle and I worked together on the research for the project for several months. We interviewed Elders from the Aboriginal and non-Aboriginal community and sought out primary source material from academics at Ballarat University. We also spoke with local artists and farmers. There were multi-layered sensitivities regarding race, history and gender, as we were aiming to tell the stories of an uncomfortable past; everything from Aboriginal people looking after the children of the miners involved in the 
rebellion, to the difficult stories surrounding the Ballarat Children's Home, which housed many Aboriginal children from the Stolen Generation. Working on this project together as Indigenous and non-Indigenous artists brought a level of credibility and experience to the project. What made the collaboration work was the strength of our relationship. We worked our way through the difficult and sometimes upsetting research material together. Each of us brought to the project our different skills. When it came to the creative work, we relied on a synchronicity that I have come to understand as 'the process' in which strange but perfect coincidences occur in the manifestation of the artwork. For example, we decided to make the work around a circle of pine trees in the botanical gardens. We covered the trees with white ochre as a part of the work to represent the death through disease and dislocation of the thousands of local Indigenous peoples during the gold rush. I found a source of white ochre in sufficient quantities in Northcote. When we began to apply the ochre, a local farmer told us that it came from a mine near to Ballarat, which had been an ochre resource for the local tribes pre-colonisation. White ochre was used for funeral ceremonies. There were a number of similar coincidences. Collaborative practice allows such synchronicity to happen because the driving force of the ego is out of the way. The strength of the relationship between the collaborators is crucial for this to happen because the problematic 'I' becomes 'we', which allows unknown and miraculous things to happen.

\section{Making collaboration work}

Collaboration is not an easy option. To make a collaborative project work takes effort from all parties, and some collaborations fail. The same can be said of any student supervisor relationship - whatever the style or approach. In this section, we will briefly outline some of the key factors that support successful collaboration.

The first and most important step is the establishment of a working relationship between those in the collaborative team. In their article 'Collaborative practice', Brien and Brady argue that 'none of the forms ... necessitates friendship' and that some collaborators can work for 'long periods in what is often referred to as a hostile situation' (Brien \& Brady 2003). While we agree that collaborators do not need to be close friends, in our experience, collaborations only work where collaborators have taken the time to build a relationship. Time spent getting to know potential collaborators before committing to collaboration is time well spent. There can be a tendency to get straight into the project, but collaboration requires a solid foundation.

Once collaborators have established a relationship and an agreement to work together, it is important to discuss and institute a process for communication and dialogue. This should happen before the project begins. It involves a discussion of differences in working styles, levels of commitment to the project and variations in vision. This is advice we have all given to potential postgraduate students about their potential supervisors - meet with them, discuss working styles and expectations and agree on a process for working through problems and issues that arise. 
For collaboration to work, it is also important that all involved commit to the process, the project and their fellow collaborators. It is crucial that those involved are willing to put forward ideas that might be discarded and at least entertain ideas that they might otherwise find unacceptable. This requires putting aside the ego. Collaborators 'have to suspend an irritable desire for control of the project, substituting instead a lover's readiness to be plastically moulded by the other's (intellectual) desire' (Carter 2007: xiii). As some collaborations do not work, there should always be an exit strategy.

\section{Supervision and collaboration}

Higher degree by research student supervision, like teaching, is hierarchical in nature and there is a general assumption that the supervisor is the 'expert' and the student the 'learner'. However, there is also substantial scholarship and best practice in teaching and learning that is based on more collaborative approaches. These could be defined as the

belief that all teaching and learning already happen - or do not - jointly, with neither teachers nor their students ... solely responsible for the success or failure, of any particular teaching and learning experience. (Brien 2007: 160)

Supervision, however, occurs within the boundaries of individual university and overarching government policies. Therefore, there is never going to be quite the same freedom available as there is in a collaborative project outside the institution. For example, the supervisors are ultimately responsible for, and therefore feel the pressure to ensure, the timely completion of students' research projects. Supervisors are aware of the expectations of potential examiners and are constrained by workload issues and the time allotted for supervision. For the student, even in the best relationship, the supervisor represents the institution. However, even under those constraints, the supervision relationship can benefit from incorporating aspects of collaborative practice as outlined above.

In the creative arts and in other fields such as those where the student's work is multidisciplinary, while the supervisor may have more experience and knowledge in some areas, he or she may have less expertise than the student in other areas. The postgraduate students we have supervised in the visual arts and creative writing have engaged with ideas ranging from racism to erotica, from blindness to cannibalism. In this, they have situated themselves within, and worked with, literary studies, cultural studies, and feminist and art theory. The best of these projects have produced innovative and challenging artworks and creative texts. The exegesis is often a hybrid, 'messy text' with multiple voices and perspectives.

Working across disciplines has many challenges, and as academics we are expected to have, or be building, expertise in particular areas, but as creative artists/writers working in practice-led research we are often treading in unfamiliar territory. The sciences have for many years recognised the impossibility of working across disciplines without collaboration: 
Part of it is a result of what's called the 'division of cognitive labor.' As science has become every-more specialized and as the number of subfields within each discipline proliferated, it's become difficult for a single person to know everything he needs to know ... Collaboration allows scientists to incorporate many different kinds of knowledge, and to do so in an active way ... Collaboration also makes it easier for scientists to work on interdisciplinary problems - which happened to be among today's most important scientific problems. (Surowiecki 2004: 161-62)

According to Johnson et al, Michael Gibbons has also argued that 'knowledge is no longer necessarily being produced by the independent scholar within the university' (Johnson et al 2000: 5) and that collaboration between academic researchers and those in industry and the community is the new mode of knowledge production. Certainly, universities and funding bodies in the arts and in academia are increasingly requiring some evidence of collaboration. It is important, then, to provide postgraduate students with experience and skills in collaboration:

$\mathrm{The} \mathrm{PhD}$ as a form of research training, in the humanities and social sciences at least, is based on the idea of the independent scholar working free from connections with the 'outside world', a dis-embedded and disembodied figure driven by the love of ideas, of scholarship, alone. With the ... new modes of knowledge production, new fantasies could begin at least to coexist with or even undermine those around the romantic figure of the scholar ... If the arguments of Gibbons et al. gain acceptance in the university context, the collaboration they claim to be emerging, as characteristic of new modes of knowledge production will require skills of learning to work with a diverse range of individuals. It will also encourage recognition of the contribution of others rather than a preoccupation with whether or not one is demonstrating the appropriate characteristics of the autonomous self. (Johnson et al 2000: 146)

While postgraduate research belongs to, and must be the work of, the individual student concerned, it has much in common with collaborative projects. It cannot, for example, be achieved without significant and engaged dialogue with others, and a joint commitment by the student and his/her supervisor/s to the project. All supervisors are aware of this whether they understand their roles as teachers, mentors, advisors or collaborators. When we consider postgraduate research in the creative arts in the context of collaboration, three specific relationships emerge: between student and supervisor/s, between co-supervisors of different disciplines and, for the student, between the theoretical and the practical aspects of the project. Reconceptualising and recontextualising supervision as collaboration, at all three levels, acknowledges joint investment in the thesis and opens up new and more dynamic ways for individuals to engage in the supervisory relationship.

In a collaborative project, the supervisor is no longer the teacher with all the answers, setting tasks for the student and then assessing them. Instead, the supervisor works with the student so that together they can discover, invent and find their way. This process allows a way of thinking through the problem that is best done in partnership (John-Steiner 2000: 1). The construction of a new way of thinking in a creative project, the inventing of a new work, benefits from this kind of collaboration - from joint commitment, ownership and responsibility. In this, it is important for both 
student and supervisor to realise that while the supervisor may have more experience at the beginning of the process, there will be a shift back and forth over time as the student's experience and knowledge grow (Nightingale 2005: 2).

There are, as we have discussed earlier, many ways of collaborating. We outlined our four models as a way of illustrating one set of possible variations. Some of our examples of collaboration have been drawn from projects situated outside of an institution. We have acknowledged that institutional structures and frameworks have an impact on the way that supervisors and students work together. From a more radical perspective, we could propose that all supervisory relationships be conceptualised as Model 4 collaborations; however, this would require a complete overhaul of the academic paradigm and the institutional structures that support it, and could necessitate a new system of research and its attribution.

Instead, working within the current institutional system, aspects of the different models of collaboration can be applied at different stages in the student's candidature. At the beginning, the student brings his/her vision to the supervisor and they work together, collaboratively, to shape this vision into a viable project. At this stage, the supervisor will have more experience and knowledge, and is likely to take a directional role. However, even at this point, it is important to use the dialogic collaborative process, for the supervisor to be prepared to listen to and work with the student's ideas. This can be challenging and even confronting, for both the more experienced senior academic supervisor and less experienced student, but it is in this initial encounter that mutual respect is established and collaborative processes are developed. As the project progresses, there is more of an equal exchange, with the student bringing new material to the supervisor and the supervisor responding and contributing further. By completion, the project is likely to be directed by the student. John-Steiner discusses such collaboration between 'professors and doctoral students':

In this relationship, we experience the temporary inequality between expert and novice. In time the relationship changes. The mentor learns new ideas and approaches from his apprentice; he adds to what he learns and transforms it. As their relationship matures, the younger and older participants build more equal connections. (2000: 151)

In the creative arts, the creative practice itself leads the research and neither the student nor the supervisor should preempt what results from this. For the supervisor to act as a teacher, mentor or advisor requires taking the lead; to act as a collaborator requires listening and engaging in dialogue. Collaboration requires supervisors to engage with the work, to observe, to make risky suggestions and to allow the student to make them as well. In such discussion, ideas will be passed back and forth - while a mentor or advisor might hold back, the collaborator will speak freely.

\section{Conclusion}

In the above discussion, we have distinguished between different models of collaboration, argued for their application in an academic context and demonstrated the benefits for creative arts supervision and research. While we have acknowledged 
that within the current institutional structures 'major' collaboration is extremely difficult to achieve, we believe that creative arts practitioners working in universities as supervisors, teachers and researchers can, by introducing 'minor' collaborative practices, play an active role in challenging and dismantling the hierarchical nature of these institutions.

The current institutional and policy frameworks, built on a militarily inflected past and designed for battle (Foucault 1979) need to be overthrown in order for the creative arts to survive and thrive. The enemy becomes a partner, the battlefield is dismantled and, to use Alison Bartlett and Gina Mercer's metaphors, we have a kitchen or a garden instead (2001). Of course, hard work is still necessary and 'there may be difficulties, even failures, but there is the probability of enjoyment in the endeavour' (Nightingale 2005: 1), as well as the creation of new ideas, knowledge and outcomes that transcend those that could be imagined by a single researcher. In such an environment, moreover, where ideas matter more than ownership, and cooperation more than territorialism, innovative creative arts research and practice are not only possible but will flourish.

\section{List of works cited}

Australian Research Council 2009 Linkages international. Available at http://www.arc.gov.au/ncgp/lx/lx default.htm [accessed 19 January 2009].

Bartlett, A and Mercer, G, eds. 2001 Postgraduate research supervision: transforming (r)elations. New York: Peter Lang.

Bigliazzi, S and Wood, S, eds. 2006 Collaboration in the arts from the Middle Ages to the present. Hampshire: Ashgate Publishing.

Brien, D L 2007 'Higher education in the corporate century: choosing collaborative rather than entrepreneurial or competitive models'. New Writing: The International Journal for the Practice and Theory of Creative Writing 4.2: 157-70.

Brien, D L and Brady, T 2003 'Collaborative practice: categorising forms of collaboration for practitioners'. TEXT 7.2 Available at http://www.textjournal.com.au/oct03/brienbrady.htm [accessed 7 January 2009].

Brown, L and Green, C 2008 '2 of us'. The Age good weekend. 6 December, Melbourne: 10.

Carter, P 2007 Material thinking: the theory and practice of creative research. Melbourne: Melbourne University Press.

Dodd, S and Gandolfo, E 2007 Inventory: on op shops. Melbourne: Vulgar Press.

Eade, L and Lunsford, A 1990 Singular texts/plural authors. Carbondale: Southern Illinois University Press.

Foucault, M 1979 Discipline and punish: the birth of the prison. New York: Vintage.

Gibbons, M, et al. 1994 The new production of knowledge: the dynamic of science and research in contemporary societies. London: Sage.

Green, C 2001 The third hand: collaboration in art from conceptualism to postmodernism. Minneapolis: University of Minnesota Press.

John-Steiner, V 2000 Creative collaborations. Oxford: Oxford University Press.

Johnson, L, Lee, A and Green, B 2000 'The PhD and the autonomous self: gender, rationality and postgraduate pedagogy'. Higher Education, 25.2: 135-45. 
Kroll, J and Brien, D L 2006 'Studying for the future: training creative writing postgraduates for life after degrees'. Australian Online Journal of Arts Education 2.1: 1-13.

Nightingale, P 2005 Advising PhD candidates. Milperra, NSW: HERDSA.

Rawlinson, M 2006 'On the losing side: Frances Stuart, Henry Williamson and the collaborationist imagination'. In S Bigliazzi and S Wood, eds. Collaboration in the arts from the Middle Ages to the present. Hampshire: Ashgate Publishing, 121-37.

Schrage, M 1990 Shared minds: the new technologies of collaboration. New York: Random House.

Surowiecki, J 2004 The wisdom of crowds: why the many are smarter than the few. London: Little Brown.

Tyan, B R = Garbett, D L 2006 'Would we, could we, did we collaborate?: mutuality and respect' $M / C$ Journal, 9.3 Available at http://journal.media-culture.org.au/0605/10-tynangarbett.php [accessed 7 January 2009].

Victoria University 'Student declaration template'. Available at http://www.vu.edu.au/library/scripts/objectifyMedia.aspx?file=pdf/550/12.pdf\&siteID=4\&str title=Stu dent Declaration Template.pdf [accessed 22 January 2009].

Victoria University 2008 Making VU 2016: a statement of purpose. Melbourne: Victoria University. Wright, S 2004 'The delicate essence of artistic collaboration'. Third Text, 18.6: 533-45. 